\title{
Witness: a response to Marlene Millar's Witness Anna Macdonald
}

Keywords: Witnessing, Mastery, Holding, Contingency, Aesthetic

I have been watching Canadian artist and filmmaker Marlene Millar's new work Witness, ${ }^{1}$ which formed part of a full retrospective of Millar's work in 2019 curated by lliyana Nedkova and produced by Horsecross Arts for Threshold artspace, Perth. It is described in the curatorial overview as a "quiet, yet poignant work inspired by Marlene's own experience as a caregiver and witness to the unfolding of her mother's dementia." 2 The film is four minutes long and involves a series of long slow-motion tracking shots that follows a woman doing simple actions such as walking, hanging up washing, and putting on lipstick. At times, she appears to dance, lifting her hands rapturously into the sky. In the middle of the film there is a single shot of an older woman, sitting looking away from the camera, tucking her hair behind her ear.

Iliyana Nedkova, the curator of the exhibition, invited me to respond to Millar's film because she felt it poses similar questions, about loss, identity and screendance, to my recent body of work, Acts of Holding. ${ }^{3}$ Millar and I are both mature female artists thinking about mortality (I was told once by a curator that he was so tired of women making work about things like death and motherhood - right before I showed him my portfolio...). Witness is part of a longer documentary and so the version I have seen acts both as a trailer for this longer film, and a screendance in its own right. Watching something that you know is an edited version of something longer sets up an interesting tension, particularly, perhaps, when it concerns a state of fragmented presence, of dementia. It also makes me aware of the importance of resisting the urge to speak for a film that is only one film from an entire exhibition, and is itself part of something larger. So, these thoughts must be taken as speculations from a restricted view, and it is the act of viewing, or more specifically the different ways Millar and I position the viewer as witness, that interests me here. ${ }^{4}$

Witness has a cinematic feel. The colour and lighting are exquisite, and the figures elegantly framed. The sound is emotive and sparse and feels made for the work. At first, I wonder if Witness is too beautiful for me? Perhaps as a throw-back to my origins in performance/video art, whilst appreciating the skill involved, I am not normally drawn to work rooted in filmic aesthetics. Although this is not the case with Witness, as I discuss further on, I associate the use of high, pin-prick resolution, often found within screendance, with a sort of mastery of the filmed body. ${ }^{5}$ To me, this seamless aesthetic can sometime feel like it subdues the contingent possibilities of the event, such as, changes in light, stumbling, changes of heart, and glitches, adding, perhaps, to what Claudia Kappenberg describes as, the "ongoing idealization of mobility in the art form." 6 
In the first online thesaurus I search for, I find the antonyms of mastery are listed as:

failure

weakness

want

lack

powerlessness

challenges

hardships

defeat

frustration

amateurishness

clumsiness

incompetence

impotence

...words that might perhaps be used to describe the experience of dementia, certainly words my mother used at times to express her frustration with terminal illness. So how does the elegant, controlled beauty of Witness relate to the difficulties of its subject?

Over repeated viewings, I see something different going on, not mastery so much as careful choices that invite me into the content of the film. The softly focused, and slowly moving, camera brings us towards, and next to, the women. Here the camera acts as a benign witness that encourages a protective way of looking and the subject is wrapped in the viewer's/artist's/daughter's warm gaze. Witness seduces us, and it is nurturing. It invites a soft way of thinking. Witness reaches forwards, reaching, allowing, testing, touching, and sensing. It feels non-verbal and I am reminded of the tactile cinema of Laura Marks where she invites us to think "of the skin of the film not as a screen, but as a membrane that brings its audience into contact with the material forms of memory." ${ }^{7}$

Another way Millar manages to employ filmic aesthetics that subvert, rather than assert, a sense of viewing as mastery, is in her merging of subject and environment. Witness offers us fingers interlacing with flower stems, feet surrounding by beans, and sun/moonlight through leaves on skin. For me there are echoes here of a feminine cinematic aesthetic, born out of Bracha Ettinger's concept of the matrixial gaze, which allows us to escape the "notion of the discrete and singular subject formed by the establishment of the boundaries that distinguish it from an oceanic or undifferentiated otherness of the world." ${ }^{8}$ The people in the film are in the world rather than using it as a backdrop for their journey as the subject/hero of the work. Even the separation between tangible and imagined/remembered worlds become blurred when the list of surfaces upon surfaces that we are offered (hands on walls, shoes on bark, fingers on hair) is broken by sequences where the woman reaches out and touches things that are not there. Touching space. Touching memories.

My screendances often involve task-based scores designed to produce movement with a sense of precarity and immediacy, and I record these events using single, static shots. If Millar 
offers a desirous body, moving and reaching through the lens then, in some ways, my work offers the opposite: the amateurish dead eye of the camera sitting un-manned upon a tripod. In responding to the curator's request to consider my practice in relation to Millar's, my work looks hard edged and unflinching, more like a search light pinning its subjects to the wall. The camera does not move or follow. It witnesses from a distance. The shots I use lack the benevolent warmth found in Millar's Witness but there is, perhaps, another form of protection in their lack of involvement. For, as I have thought about for some time now, witnessing without desire can also be a form of holding. ${ }^{9}$

Two of my works from Acts of Holding concern (perhaps as Millar's work does) the experience of witnessing my mother's terminal illness. Witness makes me question the space I often maintain between camera/viewer and subject. Perhaps I am slightly scared by the immersive quality of Witness because when the camera moves in, I feel part of me try to stay back. I realise how much easier boundaries and clarity and a bird's eye view of a situation can be for me to manage. Filming myself (and others) creates a space between my grief and myself. In the act of recording I become my own witness, holding myself, as an act of self-care, within a frame. Perhaps Millar's subjects are being pulled in against their will and there is a darker edge to the invite. It is notable that the only image we are kept away from in this version of Witness is the shot of the older lady, who we only see from behind in a static shot. This makes me want to see her more. Her earrings, the blue against the grey/white hair, are so familiar. I want to know what she is witnessing.

\section{Author Biography}

\section{Anna Macdonald}

https://vimeo.com/annamacdonald

Anna Macdonald is a screendance artist who uses film to expose the resonance of simple movements, such as, moving from 'here to there', 'holding' or 'getting slower'. She specialises in working directly with the public, using film and movement to articulate people's experiences in ways that can be understood by others. Alongside her free-lance work Anna is a Senior Lecturer in Performance at the Manchester School of Art and publishes regularly about dance, time and affect. Last year she was awarded an arts fellowship at Keele University, using screendance to re-imagine the pathways connected to the experience of chronic pain.

\section{References}

Kappenberg, Claudia. "Does Screendance Need to Look Like Dance?" International Journal of Performance Arts and Digital Media 5.2-3 (2009): 89-105. https://doi.org/10.1386/padm.5.2-3.89/1

Macdonald, Anna. "Holding and Curation." REPERTÓRIO: Teatro \& Dança 27 (2017): 49-58

. "Acts of Holding: Dance, Time and Loss."PhD by publication. Man Met University. 2019.

https://www.researchgate.net/publication/332180525 Acts of Holding Dance Time and Loss 
https://espace.mmu.ac.uk/622591/10/Acts\%20of\%20Holding\%20abstract\%20\%2B\%20title\%20page\%205th\%20 $\underline{\text { march.pdf }}$

Marks, Laura. The Skin of the Film: Intercultural Cinema, Embodiment, and the Senses. Durham, NC: Duke University Press 2000. https://doi.org/10.2307/j.ctv1198x4c

Melo, Sebastian and Nicolas Salazar Sutil. "Exposed to Time: Cross-Histories of Human Motion Visualization from Chrono- to Dynamophotography." In Rosenberg, D. (ed.) The Oxford Handbook of Screendance Studies. New York: Oxford University Press, 2016. 143-165. https://doi.org/10.1093/oxfordhb/9780199981601.013.7

Pollack, Griselda. "Thinking the Feminine: Aesthetic Practice as Introduction to Bracha Ettinger and the Concepts of Matrix and Metramorphosis." Theory, Culture \& Society 21.1 (2004): 5-65.

https://doi.org/10.1177/0263276404040479

Singh, Julietta (2018) Unthinking Mastery: Dehumanism and Decolonial Entanglements. Durham and London: Duke University Press 2018.

\section{Notes}

1 "Witness"(2019) by Marlene Millar

${ }^{2}$ Nedkova, 2019

3 "Acts of Holding" (2010-2019) by Anna Macdonald https://vimeo.com/showcase/6183450

${ }^{4}$ This writing has been developed from a blog entry, which was originally published under the name 'to witness, is not one directional' on the Threshold Arts Contemporary Arts Blog on $29^{\text {th }}$ July 2019.

https://www.horsecross.co.uk/contemporary-art/resources/contemporary-art-blog/anna-macdonald-respondsto-marlene-millars-witness. I am grateful for the on-line comments the blog received that have helped me rework this response

${ }^{5}$ There is of course a large body of discourse that examines the relationship of 'mastery' and film from both feminist and colonial perspectives. I begin to address this more directly, within an upcoming publication emerging from the 2019 Regards Hybrides: international forum, in an article entitled "Keeping in time". This article draws on Julietta Singh's analysis of mastery, "Unthinking Mastery" (2018), in relation to the act of filming a dancing body, focusing on the removal of the possibility of change, within the act of removing the body from time, in both mastery and film.

${ }^{6}$ Kappenberg, 103. Kappenberg's observation is echoed later by Melo and Sutil, “Exposed to Time", 2016

${ }^{7}$ Marks, 243

${ }^{8}$ Pollock, 6

${ }^{9}$ See Macdonald "Holding and Curation" (2017), and "Acts of Holding" (2019) 